\title{
Ethical Perceptions and Green Buying Behavior of Consumers: A Cross-National Exploratory Study
}

\author{
Pınar Bașgöze*, Öznur Özkan Tektaș \\ Hacettepe University Beytepe-Ankara, Turkey \\ pinaran@hacettepe.edu.tr*
}

\begin{abstract}
Sustainable consumption indicates preferring products that do the least damage to the environment as well as those that support ethical behavior. Therefore, this study refers and combines ethical and green issues to get a more holistic understanding of consumers' sustainable practices. The authors examine the green and ethical purchases of consumers in an exploratory and cross-national base. Semi-structured in-depth interviews were carried out with 48 American and Turkish consumers. Results reveal that both Turkish and American consumers believe that greenness is a part of ethical behavior and convert their knowledge of corporate ethics into ethical purchase. American consumers have been aware of green issues much longer than Turkish consumers have.
\end{abstract}

Key Words: Sustainable consumption, consumer ethics, green purchase, Turkey, the USA

\section{Introduction}

Over the last decade, consumer interest and awareness of sustainable consumption (SC) have grown strongly all over the world. In consumer behavior literature, SC is defined in different ways. For example, Vermier and Verbeke (2006) define SC as a decision-making process that comprises consumer's social responsibility besides their individual needs and wants. SC describes different ethical behaviors, such as animal well being and fair trade, labor standards as a societal aspect, in addition to health concerns such as an increase in organic food sales (Carrigan, Szmigin and Wright, 2004). Despite different contexts, the key players of SC are (1) ethical and (2) green consumerism where green consumption can be considered as a part of ethical consumerism (Wagner, 2002). In relevant literature, some studies (e.g. McDonald, Oates, Thyne, Alevizou and McMoral, 2009) use the terms green or environmentally friendly interchangeably referring to "sustainable consumption". As a result, examining the drivers and consequences of ethical and green product consumption, as two key players of SC, has become one of the important research areas of consumer behavior literature. In a complementary way, environmental concerns of consumers represent an important part of consumer ethics. Therefore, human-environment interaction should be invested as an ethical issue. Environment-friendly ${ }^{1}$ consumption should be characterized as a complex form of consumer behavior, and the ethical perception is an important part of it. Despite this complementary view, consumer behavior literature does not give sufficient consideration into examining ethical and green consumer behavior together. Although a few ethical research examine the green aspects of specific consumer practices (e.g. Mostafa, 2007; Chan, Wong and Leung, 2008; McDonald, et al., 2009), studies that bring green consumer practices and ethical issues together in an exploratory base is rare. In general, ethical consumers behave responsibly to society and express their feelings lay beneath these behaviors (De Pelsmacker, Driesen and Rayp, 2005). Ethical consumers have a need to increase their well-being by avoiding damaging humans, animals or environment (Carrigan et. al., 2004). Consumers should be able to examine ethical limitations of environment in order to be a green consumer (Moisander, 2007). As a part of being an ethical consumer, being a green consumer involves adopting attitudes and behaviors that are designed to minimize outcomes of one's personal purchasing, ownership, use or disposal of products in the environment (Wagner, 2002).

The idea of being both ethical and green consumer depends on Norm Activation Theory, which states that environmental feelings are derived from ethical way of thinking. Behaviors on the side of environment are influenced by moral responsibility that affects individuals' personal norms (Des Jardins, 1997; Honkanen, Verplanken and Olsen, 2006). Support for this complementary view comes from consumer behavior literature (i.e. Strong, 1996; Cowe and Williams, 2001; Honkanen et.al 2006). Yet, relatively little

\footnotetext{
${ }^{1}$ In this study, we used the terms "green, eco-friendly, environment-friendly" interchangeably; and we use "sustainable consumption" when we refer to both ethical and green consumption.
} 
research (i.e. McEachern and McClean, 2002; Chan et. al., 2008) structures green consumer behavior as an ethical issue and examine them together empirically. McEachern and McClean, $2002 ; 86)$ relate organic food purchasing and ethical decision making, and indicate that growth of ethical reasons such as the dilapidated situation of the environment, the threat to animals and human life increase the current demand for organic food products. Chan et al. (2008) present a model including teleological and deontological evaluation of ethical judgments on consumers' intentions to bring their own shopping bags when visiting a supermarket. Moreover, when discussing SC, there is a tendency to focus on individual characteristics of consumer's decision making behavior. Attitudes, preferences, and choices of individual consumers, culture and value systems may have an effect on ethic and green consumption (Thøgersen, 2010: 171; Reijonen, 2011: 405). Because, ethical consumerism is a 'motivational tendency of the individual consumer' (Papaoikonomou, Ryan and Valverde, 2011). Further, in ethical and green consumer behavior literature, little research has been done on countries such as Eastern Europe. According to Papaoikonomou et al. (2011), researches about 'micro-cultural contexts' of ethical consumption is one of the areas where it has to be empirically researched. Thus, the focus of this study has two dimensions: (1) to get a more holistic understanding of consumer buying practice by engaging ethical and green purchasing behavior, (2) to explain sustainability consciousness in a more comparable and detailed manner, we compare two different nations representing developing eastern (i.e. Turkey) and developed western (i.e. United States of America) markets. For those purposes, the study explains the consistency of ethical perceptions and green consumptions of consumers based on: (1) How well informed and aware they are on ethical and green issues; (2) what the influences and barriers of sustainable consumption are; (3) to what extend consumers are willingness to boycott a firm based on ethical issues; and finally (4) how these issues differ between a developing and a developed country.

\section{Literature Review}

Information and Awareness of Green and Ethical Issues: The increased demand for eco-friendly products and the green marketing concept in the modern era is primarily driven by rising consumer awareness about environment. Therefore, consumers forced to accept eco-friendly products. In addition, growing environmental crises have increased the environmental awareness and consciousness of both firms and consumers. Because of environmental awareness, environmental information can effect and direct consumers to make knowledgeable purchasing choices (Leire and Thidell, 2005). When consumer preferences are the subject, it can be seen that people seek for green products. Thereby, several enterprises promote green marketing (Jose, 2012). Internet is a growing medium for carrying out marketing of green messages, with print, television, mobile, and direct mail methods rising as other popular sources (Jose, 2012; Leire and Thidell, 2005; Sullivan, 2008). In recent years, numerous online green shopping sites have appeared which provides environment friendly products (Jose, 2012). In the US and Europe, increasing awareness about the environment is motivating consumers to invest in energy efficient products and recycling. Thus, this make firms to generate segmentation and positioning strategies and to initiate a successful advertising and product program linked to green issues to enhance awareness, especially in developing countries. For example, retail displays and product packaging are using "green" ideas for proper visual communication (Jose, 2012). One of the ethical issues surrounding marketing ethics studies is the awareness of consumers about ethical marketing activities of firms. According to Alexander and Nicholls (2006), in order to behave in ethical manner, consumers appear to have become more involved in achieving information about the production of purchased products. Therefore, for the companies producing ethically may attract today's knowledgeable and conscious consumers who tend to behave much more ethical ways during consumption (Wherever, 1992). Even so, a considerable part of consumers is still unaware about corporate ethical issues. For example, Carrigan and Attala (2001) give the results of Dragon International's research reporting that only $26 \%$ of respondents could give the name of a firm, which is perceived as socially responsible. That means consumer have low awareness and inadequate knowledge of unethical behaviors of firms. In addition, to understand how consumers become aware of ethical activities of firms, researchers and marketers give importance to examining the sources of information. In order to make ethical choices, consumers need true and accurate information (Uusitalo and Oksanen, 2004). Media and television are seen as the primary information sources of ethical awareness (Strong, 1996). Anon (1991) reported that, 70\% of consumers assemble information about ethical issues from television programs and documentaries in the UK, although newspapers, books and magazines are the ensuing source of knowledge. Publicity is also an important source for awareness, where negative publicity about unethical behaviors occurs more frequently than positive publicity about ethical ones (Uusitalo and Oksanen, 2004). However, according to Sun (2012) there are three barriers to being an ethical consumer: lack of information, perceived higher 
prices, and satisfaction, which can affect the awareness level of consumer. So in order to understand the awareness of consumer's ethical behavior, to examine the barriers that affect awareness is fundamental.

Influences of Ethical Issues and Boycott Behavior: In ethics literature, it is stated that ethical awareness of consumers influence their purchases both negatively and positively (Amine, 1996; Creyer and Ross, 1997). Ethical behavior of a firm leads rewarding consumption behavior via willingness to pay premium prices. In addition, according to Joergens' (2006) European consumers found small proof to support the fact that ethical issues effect purchase decisions. Somewhat, consumers' personal needs were found to be more important than ethical issues (Joergens 2006). Finally, Creyer and Ross (1997) stated that consumers beliefs about the ethical behavior of the firm as an applicable criterion in the purchase decision. On the other hand, an unpleasant outcome such as boycotts can occur if trust is violated by an unethical action or irresponsible corporate behavior (Creyer and Ross, 1997). In excess of 50\% of American respondents "punish" the unethical firm, according to a 1999 survey conducted by Associated Press (Carrigan et al., 2004). This rate has been on the increase during the last decade with the effect of increasing global awareness toward environment. Therefore, understanding positive and negative responds of consumers to ethical behaviors and attitudes of firms is essentials for both increasing and improving ethical consciousness.

Influences and Barriers on Green Buying Behavior: Green consumption behavior can be affected from some factors. For instance, consumer's green value, purchase experience, time for research, knowledge about environmental issues, affordability and green product's availability are listed as the key factors that will help green purchase (Young, Hwang, McDonald and Oates, 2009). Grankvist and Biel (2001) reveals that; increased awareness about environmental problems, price and perceived norms are three critical initiating factors of organic food purchases. As Leire and Thidell (2005) indicate, $20-50 \%$ of the consumers give priority to environmentally related issues of the products they purchase. However, it is also stated that consumers are often found to overestimate their use of product-related environmental information (Asikainen, 2000; Björk, 1997). Therefore, there is usually a gap between consumers' attitudes toward green issues and green purchasing behaviors. Further factors such as price, quality, habit, brand strength, culture, and lifestyles are other triggering factors while analyzing why green values have weaker influence on the decision making process (Biel and Dahlstrand, 2005; Sener and Hazer, 2008; Wheale and Hinton, 2007). The lack of brand loyalty on the part of green consumers entails that the green consumer always be looking for "greener" products. Shrum, McCarty and Lowrey (1995) found that if companies do succeed in attracting green-oriented consumers, they would have to work harder to keep them. Therefore, a more thorough understanding of the factors influencing green buying behavior is necessary.

National Differences: The sustainable consumption depends on some macro-level and structural factors in addition to individual consumer choices (Thøgersen 2005; Kilbourne, McDonagh and Prothero, 1997). There still exists a significant difference between developing and developed countries in terms of green awareness (Tantawi, O'Shaughnessy, Gad, Ragheb, 2009). For example, in a developed Western Society, sustainable consumption is driven, in part, by the fact that consumers are more educated, better informed, and awareness is greater of consumer rights and product requirements (Carrigan and Attala, 2001). As Mostafa (2007) indicates, personal habits and lifestyles of consumers in the US and Western Europe are becoming more environmentally responsible; yet Eastern countries, such as Egypt, are just at the stage of green awakening. Further, sustainable consumption is considered as an important aspect of sustainable development particularly in Western societies (Abeliotis, Koniari and Sardianou, 2010). Therefore, environmental safety is relatively more crucial in the developing countries. Similarly, Moisander (2007) indicates, environmental awareness increases especially in Western markets, yet there are still barriers to the green consumption styles arising from the cultural, infrastructural, political and economic circumstances. Thøgersen (2010) states consumers from northern European countries purchase more organic food than Mediterranean countries. Amine (1996) calls attention to scandals concerning production or marketing of potentially harmful products in less developed countries such as high-dosage contraceptive sales; high-pressured baby food promotions; and unhealthy production of asbestos. Besides green consumption, consumers from different nations have a propensity to analyze ethical issues in different ways (Rawwas, Strutton and Johnson, 1996). For example, Al-Khatib, Vittel and Rawwas, (1997) show that ethical beliefs of American and Egyptian consumers differ significantly. Polonsky, Brito, Pinto and Higgs-Kleyn (2001), identify differences between the consumers in Northern and Southern European Union countries in terms of ethical consumption perceptions. So, in this study, a 
comparative, cross-national perspective is used as a means to focus on the differentiation between Turkish (TR) and American (USA) green consumption and ethical purchase behavior.

\section{Methodology}

Research Questions: The study explores views of consumer experiences based on following key research questions, which are closely linked, to a qualitative research design:

- RQ1: What is the relationship between ethical issues and green buying behavior of American and Turkish consumers?

- RQ2: How well informed are the consumers on ethical issues and how much are they aware of ethical issues?

- RQ3: Are consumers will to boycott or purchase according to ethical issues of a firm?

- RQ4: How are consumers informed about green products, and are they aware of green products sufficiently?

- RQ5: What are the aspect of influences and barriers about green product purchase?

- RQ6: Are there any national differences in terms of green and ethical issues between American and Turkish consumers?

Sampling: In total, 48 respondents, 24 from Turkey and 24 from the USA, were interviewed and their responses were transcribed. Initial participators were selected conveniently from individuals who identified themselves as green and ethical consumers. After that, sample size was increased through snowball sampling method representing different age, income and education groups (Table 1), since we aimed to have a general overview and differences between two nations.

Table 1: Characteristics of the sample

\begin{tabular}{lllll}
\hline \multirow{2}{*}{ Characteristics } & \multicolumn{2}{l}{ The USA } & \multicolumn{3}{l}{ Turkey } \\
& $\#$ & \% & $\#$ & \% \\
\hline Education & & & & \\
$\quad$ High School & 1 & $4 \%$ & 3 & $13 \%$ \\
College & 11 & $46 \%$ & 12 & $50 \%$ \\
Master & 8 & $33 \%$ & 7 & $29 \%$ \\
PhD & 4 & $17 \%$ & 2 & $8 \%$ \\
Age & & & & \\
$20-25$ & 2 & $8 \%$ & 2 & $8 \%$ \\
$26-35$ & 4 & $17 \%$ & 5 & $21 \%$ \\
$36-45$ & 5 & $21 \%$ & 4 & $17 \%$ \\
$46-55$ & 4 & $17 \%$ & 6 & $25 \%$ \\
$56-65$ & 4 & $17 \%$ & 3 & $13 \%$ \\
$66-75$ & 5 & $21 \%$ & 4 & $17 \%$ \\
Gender & & & & \\
Female & 14 & $58 \%$ & 13 & $54 \%$ \\
Male & 10 & $42 \%$ & 11 & $46 \%$ \\
Income & & & & \\
Low & 4 & $17 \%$ & 4 & $17 \%$ \\
Medium & 11 & $46 \%$ & 10 & $42,5 \%$ \\
High & 9 & $38 \%$ & 10 & $42,5 \%$ \\
\hline
\end{tabular}

Method: This article adapted semi-structured, in-depth interviewing which is convenient to discover respondents' point of view about an idea or subject. An interview guide was prepared including questions covered by the guide related to the research questions outlined above. Specifically, the first part of the interview was about green consumption. We prepared 13 base questions including awareness, consumption, information sources and barriers of being green. The second part includes nine base questions about ethical issues including ethical behaviors of corporations, boycott behavior of participants, information sources, and influences of being ethical consumer. The interviews were conducted simultaneously in Turkey and in the USA. Interviews typically lasted about 40-50 minutes and were conducted by the researchers of this study. Since the expression of the ideas, attitudes and beliefs in native language is important and easier, in both countries the interviews were conducted in native languages. 
Reliability and Construct Validity: For the reliability of the study (Seidman, 2006; Wagner-Tsukamoto, 2009), all parts of the interviews were audio-recorded with the permission of participants and transformed into a written test to study. The interview data was transcribed word-by-word and outlined in detailed how the coding and interpretation were done. It is stated (i.e. Chikudate, 2000; Dentchev, 2004) that the "variance saturation" should be considered for the construct validity, and the range of 1218 interviewees should be assessed for the saturation. Hence, in total 48 (24 for each country) interviews were conducted. Further, for the sake of validity, we separated the process of gathering and analyzing data (Seidman 2006), and started to analyze the data after interviews in both countries have been completed.

Analyzing: Wagner's (1997) qualitative research analysis process was followed for the interpretation of interviews. According to this process, first we transcribed recorded interviews into words and named each participant. The USA participants were named as US01, US02, US24; and the Turkish participants were named as TR01, TR02, and TR24 chronologically. After transcribing, we used bracketing framework to analyze the data. For this framework, variables and codes are selected in line with the interview questions and research questions under investigation. In this stage, the interview data was read repeatedly and searched for coded groups. By noting iterations, key phrases, thematic patterns and similarities were described. After a separate investigation of two countries, the data was re-searched for the cultural variances.

\section{Results and Discussion}

As a general overview, entire findings are given by considering the differences between two countries. Therefore, the study revealed that there are some identifiable differences between American (US) and Turkish (TR) consumers in terms of both green and ethical issues. Here are the findings and related discussion of our in-depth interviews mainly focusing on the differences between two countries:

Information and Awareness of Green Issues: It is seen that one of the most significant differences between two-country consumers is the level of consciousness about green issues. While $66 \%$, of US, consumers have an idea and consideration about green issues more than 10 years, this ratio is $30 \%$ for TR consumers. Moreover, while $40 \%$ of US participants actively purchase green products for more than 10 years, this ratio is almost half of that for TR consumers. Thus, we can conclude that US consumers are more conscious and active in buying green products than TR consumers.

- (US05): It has been a long long time... since I was 24. My mother had a small recycling center. I buy green products since early 1970s. I try to buy laundry soaps; it was probably the first green product.

- (TR05): It is a new issue for me, before the last 5 years I did not know anything about green or organic products. Five years ago, I started to buy green detergent.

- Further, relatively small volume of green market share may be one reason for TR consumers' lack of knowledge and green behavior:

- (TR14): It is hard to find green products because not every supermarket is selling them.

- (TR04): ... For example, there are limited alternatives; especially in cosmetics, I cannot find enough green choices. If there were more alternatives, green purchase may become a habit.

- About the market share, following example may give an idea of US consumers' consciousness level:

- (US22): Most people do not have the money to buy organic foods because they are expensive. Everybody should keep 10\% of their food budget and buy as much organic food as they can. Because the only way green products to get cheaper is farmers to have more market. If everybody in the United States spends 10\% of their food budget to organic foods, the market will increase and prices will come down.

- Most of the interviewees use internet and newspaper respectively as information sources of being green in addition to product is itself. Word of mouth among their friends and family was the third information sources. They do not trust television commercials and salespeople.

- (TR18): The first and the most important source of information for me is the internet. I always use user forums appearing in the internet. In addition, idea of my friends and family means a lot to me. However, I do trust a little to television.

- (US09): I definitely collect information, I use internet. First, I go online and read consumer reports. They are useful. I ask my friends or people who have knowledge. I probably absorb information from advertising or salespeople, but I am skeptical about these kinds of information sources. About supermarket, that depends on the reputation of the supermarket. 
Information and Awareness of Ethical Issues: We examine ethical issues based on two important heading: Participants' ethical perceptions about themselves as consumers, and their attitudes and behavior toward corporate activities. From the interviews, it was apparent that there are certain ethical issues that consumers consider as important signs of being ethical and as influences of their purchase behavior. In total $70 \%$ of US consumers and $71 \%$ of TR, consumers report that they consider ethical issues while making their buying decision. Yet, similar to green purchase, there is about $10 \%$ (lower than being green) attitude-behavior gap for ethical issues. The general feeling was that, in both countries this attitude-behavior gap was reported to result from lack of knowledge:

- (TR18): It is not possible for me to know the production process of the firm. In addition, I have no idea about underage employees. Therefore, I can only decide whether a firm is ethical or not through the materials that are used in the product and if it writes on the product, maybe I can know about the tests that are made.

- (US19): I would love to be a truly ethical consumer but the fact is I really do not know what companies are doing. In addition, unless the information about those companies is on the news I do not go and look for it.

Consumers learn ethical events mostly from TV news and newspapers, from internet and from their own experiences. When we examine the barriers of being an ethical consumer, lack of knowledge was appeared as the most important reason for not considering ethics during purchasing decision. Most of the participants do not have the knowledge of distinguishing ethical and unethical firms. More importantly, participants from both countries believe that this lack of knowledge cannot be fulfilled totally, since the firms can control the information shared with public.

- (TR16): If the media gives this kind of information, I could know it and pay attention. Otherwise, we have no chance to have this kind of ethical information.

- (US13): It is hard to know what the companies are doing. I really know they do lots of thing that are secret but they try to keep it quite. They hire lawyers and PR people to protect them. It is hard to know what is going on.

The second barrier for US participants was that being an ethical consumer is a hard work because it needs time, energy and research; it is easier to forget about and not to be. Further, some of them believe that the design of the community sometimes forces people to forget about ethics.

- (US02): I guess I should do more research about every product or firms and find out, but I think we do not have the time or do not think about it. It takes time to be a skeptical consumer.

- (US05): ...Yes, it is hard to be an ethical consumer. In the United States, there is a lot of pressure to get the best deal possible for you. So people cheat so much and they stress on money and materialism. This makes it hard to be an ethical consumer.

On the other hand, although some of TR participants (who consider being ethical and being green equal) find being an ethical consumer is more costly; majority of the TR participants (71\%) believe that it is not hard to be an ethical consumer. Because they believe, being ethical is a personal and social value.

- (TR01): It is not hard to be an ethical person because it is relevant to personal values and personality. Social and personal values make you an ethical consumer and you learn these values from society and your family.

- (TR03): Being an ethical person is about social values.

Influences of Ethical Issues and Boycott Behavior: Consumers can express their positive and negative way of thinking by means of purchasing behavior such as positive buying or boycott campaigns. The overall impression is that, our participants tend to punish unethical firms rather than rewarding ethical ones. They translate their ethical concerns by means of boycotting products for their negative qualities (e.g. not buying the products of firms using animal testing); but not by means of positive buying (e.g. buying fair-trade products). The reason that our participants do not reward ethical firms is obvious that consumers can hardly remember an ethical firm or brand name while they could recall unethical firms much more easily.

- (US13): It is harder to remember an ethical company. I do not know if ethical companies are always bragging that they are ethical. I am sure there are tons of ethical companies, which are just making their jobs.

Even if they remember more easily, the knowledge of unethical behaviors of firms is limited with the activities of 3-4 firms. For instance, BP oil spill is the most commonly known unethical event where it is 
followed by Enron scandal and Nike's employment of child workers. Exxon, Nestle Baby formula, and mine disasters are other unethical events remembered by US consumers. Large majority of TR participants remembered Nike, BP and Gap as unethical firms. Consumers learn these kinds of events mostly from TV news and newspapers, from internet and from their own experiences. Majority of the US $(91 \%)$ and TR participants (88\%) reported that they would boycott the products of an unethical firm if they find out even it is their favorite brand.

- (TR09): If a firm behaves in an unethical manner, than I boycott the firm. In addition, I do negative word of mouth and do not buy the products of that firm. Even if this product is my favorite, I boycott the firm. For example, when L'Oreal acquired Body Shop, I suspended buying the products of Body Shop because I could not trust that they do not test the product on animals.

Influences and Barriers on Green Buying Behavior: Supporting previous studies (i.e. Young et. al. 2009), our interviews show there is about a $20 \%$ attitude-behavior gap in green issues. Consumers report that they concern or have consciousness about environmental issues, yet they struggle to translate into behavior:

- (US14): Well, for thinking I would like to think I concern environment 90\%, but for acting I know I am probably somewhere on 50\%. In addition, I can say the same think for thinking and behaving as an ethical consumer.

We believe that the reason for this gap may be some influences and barriers of green buying habits. Given their expressed interest in green purchasing, it was interesting to find that when asked "what is the most important influence on their purchase behavior?"; price, needs, quality and value are still the most important factors of buying behavior for both countries.

- (TR07): Need for this product is essential. I buy a product if it is functional and if the product fulfills my need.

- (US05): Quality is a big factor. I guess I also have to say value. Paying the money for getting the best quality.

- (US14): In general, need, affordability would be top two concerns. Others would include the quality of the product, cost-benefit; I mean value of the product.

- Consumers are not willing to purchase green product if price and quality are significantly affected.

- (US15): ...Dish washer machine soap, I tried green version but it did not work.

- (TR20): Recycled products seems less qualified to me.

About the price, consumers have a comfort zone of how much more they are willing to pay for green version of products. Moreover, there are differences as to the reported willingness to pay a price premium for different product groups. In both countries, consumers are willing to pay more for and place more value on products' sustainability performance in the case of high involvement, less frequently purchased appliances than in the case of frequently purchased products such as groceries. For example, American consumers agreed to a price increase of $10-20 \%$ for grocery products, but $30-50 \%$ for durable goods. Energy consumption level is the most important issue for consumption of green appliances. Yet, they consider saving primarily for financial reasons, not for the environment.

- (TR20): When purchasing a grocery product the greenness of the product is not important for me. While purchasing fundamental products most influential factor is price according to me. However, I pay much more money when purchasing appliances. So I pay attention to energy saver ones.

- (US24): Except organic foods, I do not think about environment. I think about me. The reason is usually the price. Usually they are more expensive. For durable goods, I consider especially energy saving but mostly for my budget.

- (US14): ...to be honest, I buy energy saving appliances not because it is better for the environment but because they save my budget in the end. To make money in other words, it is often an investment to buy energy saving appliances.

Most of the participants agree that green consumption is a hard work because of some barriers. Some of them believe that it is a very time consuming process since they need to search for the options, they need to find out the places that sell green products, and they feel lack of knowledge about the firms and products.

- (US01): It is expensive to be a green consumer ... and recycling, flatten the boxes; going to green supermarkets, that entire green staff is time consuming. Many people do not want to take that time. 
- (US19): I do have to say that time is a factor in buying green products. Because sometimes I do not have the time to go to local farmer market for buying organic foods for example, and I just buy from the supermarket. In addition, cost is really a factor for especially organic foods because they are three times more expensive.

- The other significant barrier emerged was lack of choice and knowledge. More than half of the participants in both countries feel lack of choice when they think about green products and they find it difficult to understand whether a product is green or not.

- (TR20): If it does not write that product is a green version than I could not understand if the product is green or not.

- (USO3): ... I think I understand the labels. However, I feel lack of choice when I think about green products. It is very difficult to find the corner that has all of organic staff in it.

- (US19): It is definitely difficult to decide if a product is a green product or not. Especially cleaning products, they have many ingredients and it is very complicated. In addition, these green labels are only partially true. For example, it is written "biodegradable" on the label, but for producing it, they use many petroleum products.

- Further, the majority of the participants believe that being a fully green consumer is a hard work:

- (US12): I do believe that being a green consumer is a hard work. The biggest thing is the time. You know people are so in rush. To be an intelligent green consumer takes time, you have to research many things.

- Some in-store factors such as self alignment can be effective for consumers while evaluating green products:

- (US06): I would like to see environmentally friendly products on the shelf next to the real product. However, supermarkets put all organic products in one area of the store together in one shelf or isle in the store. I wish they were side by side on the shelf that you could compare the products and alternatives. Maybe I have other, for example, biodegradable, alternatives but I do not see them.

The other significant barrier was lack of habit for both countries. Consumers just buy the same brand they are used to, they do not think about it so much.

- (TR13): To be a green consumer is not so hard, but purchasing a green product is hard because green products are much more expensive than other products. In addition, it has to be a habit; in Turkey, we do not have such kind of habit. People typically prefer low-priced products.

- (US12): It is hard to be truly green. Our culture has big cars; lots of packaging so design of the community sometimes makes it difficult. Not set up to be green.

- Trust is another barrier. Some consumers in both countries believe that green issues are used by firms as a marketing tool. It may be explained by insufficient information:

- (US05): About 40 years ago, people were encouraged to use healthy laundry soaps but now it is a skeptical marketing device for me. Because many products that are build as green or environmentally friendly that truly not! Firms producing green products use lots of packaging...Also I look where is it made and transportation cost.

- (US22): Because the environmental issue is such a big political issue in the United States, I always suspect that there is business and politics behind it to make money and I don't know exactly the truth and don't trust it.

\section{Conclusion}

The purpose of this study is to investigate (1) How well informed and aware they are on ethical and green issues; (2) what the influences and barriers of sustainable consumption are; (3) to what extend consumers are willingness to boycott a firm based on ethical issues; and finally (4) how these issues differ between a developing and a developed country. To capture a valuable insight into green and ethical consumer behavior the findings of this exploratory study provide a cross-national focus. First, overall results in both countries show consumers believe that green purchasing is a part of ethical behavior. In addition, literature suggests that Ethical, or 'green' consumerism as it is more commonly referred to, same behavioral phase of consumer purchasing behavior (McEachern and McClean, 2002). Especially the majority of Turkish participants consider being a green consumer same as being an ethical consumer. Therefore, marketing managers should use their ethical and green issues together while shaping their marketing strategies and try to convince shoppers that sustainable consumption including both green and ethical behavior brings long-term profit. What differed by the country is the duration of being a green consumer, and the level of consciousness about green issues is more evident for American consumers 
than for Turkish consumers. To answer why Turkish consumer has a low level of consciousness about green issues, this study reveals some reasons: In Turkey, green issues are still not at the primary level of needs of hierarchy. As it is stated in the literature (Biel and Dahlstrand, 2005; Sener and Hazer, 2008; Wheale and Hinton, 2007) factors such as price, quality, habit, brand strength, culture, and lifestyles can be much more effective on the decision making process. Moreover, Turkish consumers have less trust to green issues, due to the lack of availability of specialized information sources, green labels and formal or informal education about green issues. These are relatively new issues in Turkey and therefore there is a lack of necessary infrastructure for being green consumer. For instance, recycling is not systematic and can be very time consuming. Relatively small volume of green market share may be another reason for Turkish consumers' lack of knowledge and green behavior. Therefore, firms should be aware of green consciousness of the nation and generate their green marketing strategies according to this consciousness level. If a nation has little consciousness and knowledge about green issues, it would be better to generate an education program on marketing strategies of green products first.

Our findings also suggest that although consumers believe they should consider ethical and green issues during their purchasing decisions; they hardly translate their sustainable consumption knowledge into behavior. The attitude-behavior gap is well documented in the reviewed consumer behavior literature (i.e. Young et. al. 2009). Our results support that conception. Consistent with previous studies (i.e. Carrigan et al. 2004), one possible reason of this gap is consumer priorities. With the existing evidence, price, needs and value for money are stronger motivations for purchasing than green or ethical considerations. It will be meaningful for marketers to emphasize that green products are high quality enough to purchase, and their purchase behavior can make a difference in ethical terms. Marketers also need to increase consumers' awareness level for green products and they need to offer green consumption as a part of ethical consumer behavior, which needs special strategies to make consumers feel rewarded when they make sustainable consumption. Increasing the market potential may also solve the high-price and lack of choice problem. Another significant barrier for attitude-behavior gap is lack of habit for both countries. Because according to the literature habits are a function of an individual's experience and Hunt and Vitell, (1986) argue that personal experiences affect ethical behavior. The available evidence suggest that, consumers just buy the same brand that they are used to, they don't think about it very much. They express willingness to purchase green products but do not wish to be inconvenienced in order to do so. Further, consumers find being green is a time consuming activity, and they feel lack of alternatives when they think about green products. There are other important gaps in our understanding of the differences between countries in source of information for both green and ethical consumption. The findings reveal that internet remains an important source of information in both countries; consumers discover green products from internet and newspaper. This finding is parallel with the literature (Jose, 2012; Leire and Thidell, 2005; Sullivan, 2008). Consumers, especially in Turkey, need credible, accessible and reliable information for their sustainable purchase decisions. Credibility is an important factor for decision making for selecting a product (Gotlieb, Schlacter and Louis, 1992). Consumers much more tend to purchase products that they are familiar with. In the USA, labels are effective in consumer green purchase, but in Turkey, they have limited knowledge about labels. Therefore, in developing countries such as Turkey, firms should bring out labels of green products and educate consumers about these labels. To become a significant influence on sustainable consumer behavior, firms need to increase knowledge of labels, develop more effective distribution zones, and provide more choices of green products. In this way, barriers of sustainable consumption, such as lack of knowledge, time and choice, can be reduced.

In parallel with previous research (e.g. McDonald et al., 2009), our results highlight that consumer's attitudes toward green products vary between product classes. The USA consumers are willing to pay more price premium and place more value on product's sustainability performance in the case of high involvement, less frequently purchased appliances than in the case of frequently purchased products such as groceries. For both countries, Energy consumption level is the most important issue for consumption of green appliances, yet, they consider energy saving primarily for personal financial reasons, not for the environment. Some product groups are more strongly linked to green issues: for example, organic and local food and cleaning supplies are the most purchased green product groups. When it comes to evaluating ethical behavior of corporations, our results state that both Turkish and American consumers have a strong sense of moral responsibility that is reflected in their ethical purchasing behavior. US consumers appear to be a more educated society, with informed opinions such as poor worker rights, discrimination, child worker and unethical business practices. Although consumers express a desire to support ethical companies and punish unethical ones, they state that they could not know about ethical 
behaviors of a firm. In other words, the most important barrier to ethical consumerism appears to be the difficulties in obtaining information. Most of the participants believe they do not have the knowledge of distinguishing ethical and unethical firms. This finding is consistent with reviewed literature (Carrigan and Attala, 2001). Further, consumers usually punish unethical firms, but hardly reward ethical ones. Therefore, firms should make their customers feel rewarded when make purchases on ethical reasoning and encourage them to build healthier ethical decisions as a habit in the society.

Limitations and Future Research: This study has some limitations, and raises additional questions for future research as well. First, when in-depth interviews are conducted, generalizations about the results are usually not able to be made because of small samples and not using random sampling methods. Further research can overcome this limitation by taking into account bigger size of sample and quantitative methods. The role of the researchers as interpreters should also be taken into account for generalization. Second, individual factors such as gender, age, income and life-style may play an important role and require attention in future research. Our interviews give some clues about the impact of some factors on sustainable consumption. For instance, an American participant declared that "...If I were a millionaire, I would be a more exclusive green buyer". Future studies may emphasize more specific concepts such as the influence of gender, age, income and life-style on sustainable consumption, which is stated as combination of green and ethic buying behavior.

\section{References}

Abeliotis, K., Koniari, C. \& Sardianou, E. (2010). The profile of the green consumer in Greece. International Journal of Consumer Studies, 34, 153-160.

Alexander, A. \& Nicholls, A. (2006). Rediscovering consumer-producer involvement: A network perspective on fair trade marketing. European Journal of Marketing, 40(11/12), 1236-1253.

Al-Khatib, J., Vitell, S. J. \& Rawwas, M. Y. A. (1997). Consumer ethics: A cross-cultural investigation. European Journal of Marketing, 31, (11/12), 750-767.

Amine, L. S. (1996). The need for moral champions in global marketing. European Journal of Marketing, $30(5), 1-12$.

Asikainen, J. (2000). Environmental labeling as means to affect consumer choices e case of Nordic swan. Helsinki School of Economics and Business Administration, Department of Marketing/Logistics. March, 1-26.

Biel, A. \& Dahlstrand, U. (2005). Values and habits: a dual-process model. In S. Krarup, C. S. Russell \& E. Elgar (Ed.) Environment, Information and Consumer Behavior, Cheltenham, 33-50.

Björk, P. (1997). The effect on green labels on consumer decision making. Svenska Handelshögskolan, Swedish School of Economics and Business Administration, 1-29.

Carrigan, M. \& Attala, A. (2001). The myth of the ethical consumer - do ethics matter in purchase behavior? Journal of Consumer Marketing, 18(7), 560-577.

Carrigan, M., Szmigin, I. \& Wright, J. (2004). Shopping for a better world? An interpretive study of the potential for ethical consumption within the older market. Journal of Consumer Marketing, 21(6), 401-417.

Chan, R. Y. K., Wong, Y. H. \& Leung, T. K. P. (2008). Applying Ethical Concepts to the Study of Green Consumer Behavior: An Analysis of Chinese Consumers_ Intentions to Bring their Own Shopping Bags. Journal of Business Ethics, 79, 469-481.

Chikudate, N. (2000). A Phenomenological Approach to Inquiring into an Ethically Bankrupted Organization: A Case Study of a Japanese Company. Journal of Business Ethics, 28, 59-72.

Cowe, R. \& Williams, S. (2001). Who are the Ethical Consumers? Co-Operative Bank/Mori Survey, Cooperative Bank, London, UK.

Creyer, E. H. \& Ross, W. T. (1997). The influence of firm behavior on purchase intention: do consumers really care about business ethics? Journal of Consumer Marketing, 14(6), 421-33.

De Pelsmacker, P., Driesen, L. \& Rayp, G. (2005). Do Consumers Care about Ethics? Willingness to Pay for Fair-Trade Coffee. The Journal of Consumer Affairs, 39(2), 363-385.

Dentchev, N. A. (2004). Corporate Social Performance as a Business Strategy. Journal of Business Ethics, $55,397-412$.

Des Jardins, J. R. (1997). Environmental Ethics. Belmont, CA: Wadsworth Publishing Co.

Grankvist, G. \& Biel, A. (2001). The importance of beliefs and purchase criteria in the choice of eco-labeled food products. Journal of Environmental Psychology, 21, 405-410. 
Gotlieb, J., Schlacter, J. \& Louis R. (1992). Consumer Decision Making: A Model of the Effects of Involvement, Source Credibility and Location on the Size of the Price Difference Required to Induce Consumers to Change Suppliers. Psychology and Marketing, 9, 191-208.

Honkanen, P., Verplanken, B. \& Olsen, S. O. (2006). Ethical values and motives driving organic food choice. Journal of Consumer Behavior, 5(5), 420-30.

Hunt, S. D. \& Vitell, S. M. (1986). A general theory of marketing ethics. J. Macromarketing, 6(1), 5-16.

Joergens, C. (2006). Ethical fashion: myth or future trend? Journal of Fashion Marketing and Management, $10(3), 360-371$.

Jose, S. (2012). Rising Consumer Awareness on Environment Issues to Stimulate the Demand for Green Marketing, According to New Report by Global Industry Analysts, Inc. http://www.prweb.com/releases/green_marketing/ecological_marketing/prweb9449966.htm

Kilbourne, W., McDonagh P. \& Prothero, A. (1997). Sustainable consumption and the quality of life: A macro marketing challenge to the dominant social paradigm. Journal of Macro-marketing, 17, 424.

Leire, C. \& Thidell, A. (2005). Product-related environmental information to guide consumer purchases - a review and analysis of research on perceptions, understanding and use among Nordic consumers. Journal of Cleaner Production, 13(10/11), 1061-70.

McDonald, S., Oates, C., Thyne, M., Alevizou, P. \& McMorland, L. A. (2009). Comparing sustainable consumption patterns across product sectors. International Journal of Consumer Studies, 33, 137145.

McEachern, M. G. \& McClean, P. (2002). Organic purchasing motivations and attitudes: are they ethical? International Journal of Consumer Studies, 26(2), 85-92.

Moisander, J. (2007). Motivational complexity of green consumerism. International Journal of Consumer Studies, 31(4), 404-409.

Mostafa, M. M. (2007). Gender differences in Egyptian consumers' green purchase behavior: the effects of environmental knowledge, concern and attitude. International Journal of Consumer Studies, 31, 220-229.

Papaoikonomou, E., Ryan, G. \& Valverde, M. (2011). Mapping Ethical Consumer Behavior: Integrating the Empirical Research and Identifying Future Directions. Ethics \& Behavior, 21(3), 197-221.

Polonsky, M. J., Brito, P. Q., Pinto J. \& Higgs-Kleyn, N. (2001). Consumer Ethics in the European Union: A Comparison of Northern and Southern Views. Journal of Business Ethics, 31, 117-130.

Rawwas, M. Y. A., Strutton, D. \& Johnson, L. W. (1996). An exploratory investigation of the ethical values of American and Australian consumers. Journal of Direct Marketing, 10, 52-63.

Reijonen, S. (2011). Environmentally friendly consumer: from determinism to emergence. International Journal of Consumer Studies, 35, 403-409.

Seidman, I. (2006). Interviewing As Qualitative Research: A Guide for Researchers in Education and the Social Sciences. Teachers College, NY.

Sener, A. \& Hazer, O. (2008). Values and Sustainable Consumption Behavior of Women: A Turkish Sample. Sustainable Development, 16, 291-300.

Shrum, L. J., McCarty, J. A. \& Lowrey, T. M. (1995). Buyer Characteristics of the Green Consumer and Their Implications for Advertising Strategy. Journal of Advertising, 24(2), 71-82.

Strong, C. (1996). Features contributing to the growth of ethical consumerism - a preliminary investigation. Marketing Intelligence \& Planning, 14(5), 5 -13.

Sullivan, J. (2008). Green? Who Says So? Builder, April, 24.

Sun, E. (2012). Environmental groups foster consumer awareness alongside NYU, Hunter College, http://www.columbiaspectator.com/2012/04/09/environmental-groups-foster-consumerawareness.

Tantawi, P., O'Shaughnessy, N., Gad, K. \& Ragheb, M. A. S. (2009). Green consciousness of consumers in a developing country: A study of Egyptian consumers. Contemporary Management Research, 5(1), 29-50.

Thøgersen, J. (2005). How many consumer policy empower consumers for sustainable lifestyles? Journal of Consumer Policy, 28, 143-78.

Thøgersen, J. (2010). Country differences in sustainable consumption: The case of organic food. Journal of Macro marketing, 30(2), 171-185.

Uusitalo, O. \& Oksanen, R. (2004). Ethical consumerism: A view from Finland. International Journal of Consumer Studies, 28(3), 214-221.

Vermier, I. \& Verbeke, W. (2006). Sustainable Food Consumption: Exploring the Consumer AttitudeBehavioral Intention Gap. Journal of Agricultural and Environmental Ethics, 19, 169-194. 
Wagner, A. S. (1997). Understanding Green Consumer Behavior: A Qualitative Cognitive Approach. Routledge, NY.

Wagner-Tsukamoto, S. (2009). Consumer Ethics in Japan: An Economic Reconstruction of Moral Agency of Japanese Firms - Qualitative Insights from Grocery/Retail Markets. Journal of Business Ethics, 84 (1), 29-44.

Wagner, S. A. (2002). Understanding Green Consumer Behavior: A Qualitative Cognitive Approach, New York: Taylor \& Francis e-Library.

Wehrmeyer, W. (1992). Reviewing Corporate Environmental Strategy: Patterns, Positions and Predicaments for an Uncertain Future. In Charter, M. \& Polonsky, M. D. (Ed.) Greener Marketing, 41-56, Greenleaf, Publishing, Sheffield, UK.

Wheale, P. \& Hinton, D. (2007). Ethical consumers in search of markets. Business Strategy and the Environment, 16, 302-315.

Young, W., Hwang, K., McDonald, S. \& Oates, C. J. (2009). Sustainable consumption: green consumer behavior when purchasing products. Sustainable Development, 18(1), 20-31. 